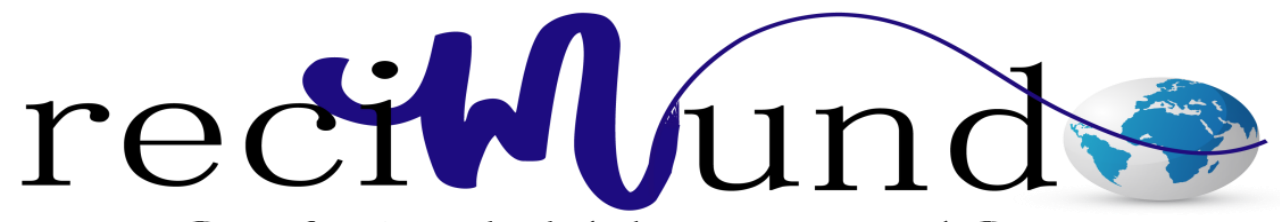

Revista Científica Mundo de la Investigación y el Conocimiento

Elvis Guillermo Fuentes Tenorio ${ }^{\mathrm{a}}$; Marisol Katherine Castro Herrera ${ }^{\mathrm{b}}$; Susana Brasilia Cedeño Solórzano ${ }^{\mathrm{c}}$; Leopoldo Javier Larrea Simball ${ }^{\mathrm{d}}$

El Abuso de los Jueces y Juezas al Dictar la Prisión Preventiva en Ecuador

Revista Científica Mundo de la Investigación y el Conocimiento. Vol. 1 núm., 4, septiembre, 2017, pp. 822-837

DOI: 10.26820/recimundo/1.4.2017.822-837

Editorial Saberes del Conocimiento
a) Universidad de Guayaquil.
b) Universidad de Guayaquil.
c) Universidad de Guayaquil.
d) Universidad de Guayaquil. 


\section{El Abuso de los Jueces y Juezas al Dictar la Prisión Preventiva en Ecuador}

Vol. 1, núm. 4., (2017)

Elvis Guillermo Fuentes Tenorio; Marisol Katherine Castro Herrera; Susana Brasilia Cedeño

Solórzano; Leopoldo Javier Larrea Simball

\section{RESUMEN}

Este artículo explora el abuso que los jueces y juezas realizan al dictar la prisión preventiva en nuestro país llamado Ecuador.

Las relaciones entre los infractores y las medidas alternativas a la prisión preventiva considerada por muchos tratadistas como una forma de pena anticipada debe dictarse de manera racional no se puede sobre poblar las cárceles con el pretexto de combatir la delincuencia. Tenemos una sociedad degrada en sus valores, por un sistema político sustentado en la simulación y en la inmoralidad, que sueña con un cambio en el sistema judicial, político y económico, que conllevaría a mejorar la mala situación que atravesamos y que ha causado serios daños a nuestra sociedad. Por tal motivo nuestra sociedad exige repuesta inmediata de la justicia sobre la delincuencia y el sistema judicial que actúa pero lo hace con venganza considerando a todos los casos como graves que alarman a la sociedad. Esta forma equivocada de aplicar la justicia conlleva a que los jueces y juezas abusen al dictar la prisión preventiva.

La justicia debe actuar ya que como parte del estado no puede dejar a un lado su responsabilidad de atender primordialmente la protección integral de sus ciudadanos y ciudadanas, pero no se debe convertir en su más brutal amenaza a las personas que han cometido un delito porque tienen los mismos Derechos Humanos que todas las demás personas; por tal razón señores jueces y juezas no abusen de la prisión preventiva no se olviden que las responsabilidades son compartidas y si se llegare a determinar la violación a los derechos humanos de los ciudadanos detenidos el estado sería responsable de lo que sus funcionarios hagan o dejen de hacer pero ustedes podrían responder con una repetición. Muchas personas privadas de su libertad y en especial grupos vulnerables como los afroecuatorianos, montubios, indígenas y en particular las personas más pobres de nuestro país sufren el abuso de los jueces y juezas al momento de dictar indiscriminadamente la prisión preventiva.

Palabras clave: Prisión preventiva; abuso por parte de jueces y juezas. 


\section{El Abuso de los Jueces y Juezas al Dictar la Prisión Preventiva en Ecuador \\ Vol. 1, núm. 4., (2017) \\ Elvis Guillermo Fuentes Tenorio; Marisol Katherine Castro Herrera; Susana Brasilia Cedeño Solórzano; Leopoldo Javier Larrea Simball}

\section{ABSTRACT}

This article explores the abuse that judges and judges make when dictating pretrial detention in our country called Ecuador.

The relationship between offenders and alternative measures to pretrial detention considered by many writers as a form of early punishment must be dictated rationally can not be populated prisons under the pretext of combating crime. We have a society devalued in its values, by a political system based on simulation and immorality, that dreams of a change in the judicial, political and economic system, that would lead to improve the bad situation that we are going through and that has caused serious damages To our society. For this reason, our society demands an immediate response from the justice system about crime and the judicial system that acts, but it does so with revenge, considering all cases as serious that alarm society. This wrong way of applying justice leads to judges and judges abusing when dictating pre-trial detention.

Justice must act because, as part of the state, it can not leave aside its responsibility to primarily address the integral protection of its citizens, but it must not become its most brutal threat to persons who have committed a crime because they have The same Human Rights as all other people; For that reason, judges and magistrates do not abuse pretrial detention do not forget that responsibilities are shared and if the human rights violation of arrested citizens is determined, the state would be responsible for what its officials do or do not Do but you could respond with a repetition. Many people deprived of their liberty and especially vulnerable groups such as AfroEcuadorians, Montuzzi, Indigenous people and particularly the poorest people in our country suffer abuse of judges at the time of indiscriminately imprisonment.

Keywords: Detention; abuse by judges. 


\section{El Abuso de los Jueces y Juezas al Dictar la Prisión Preventiva en Ecuador}

Vol. 1, núm. 4., (2017)

Elvis Guillermo Fuentes Tenorio; Marisol Katherine Castro Herrera; Susana Brasilia Cedeño Solórzano; Leopoldo Javier Larrea Simball

\section{Introducción.}

La constitución del 2008, que rige en nuestro país es garantista de los derechos de los ciudadanos, por tal motivo en su Art. 77.- numeral 1, nos dice que "En todo proceso penal en que se haya privado de la libertad a una persona, se observarán las siguientes garantías básicas:” La privación de la libertad se aplicará excepcionalmente cuando sea necesaria para garantizar la comparecencia en el proceso, o para asegurar el cumplimiento de la pena; procederá por orden escrita de jueza o juez competente. (Asamblea Constituyente del Ecuador, 2008)

En los casos, por el tiempo y con las formalidades establecidas en la ley. La constitución de la república le está diciendo al juez o jueza usted puede hacer uso de la prisión preventiva pero de manera excepcional, cuando no tenga otra alternativa, pero primero ustedes como autoridades judiciales deben utilizarse las otras medidas alternativas a la prisión preventiva. En este mismo art. Se exceptúan los delitos flagrantes, en cuyo caso no podrá mantenerse a la persona detenida sin fórmula de juicio por más de veinticuatro horas. Si se puede mantener a una persona detenida solo por veinticuatro horas en los delitos flagrantes o sea personas se son detenidas inmediatamente una vez cometido el delito, pero el juez o jueza tiene que calificar la flagrancia y si cree pertinentes dictar medidas alternativas a la prisión preventiva tal como lo determina la Constitución de la República y de ser necesario y no habiendo ninguna posibilidad de dictar medidas alternativas a la prisión preventiva el juez o jueza podría hacer uso de esta medida que es una de la más fuerte establecida en nuestro ordenamiento jurídico penal ya que se priva a una persona quitando lo más preciado de todo ser humanos cuál es su libertad, y violando su principio de inocencia .Pero los jueces por temor a perder sus puestos de trabajo, no utilizan las medidas alternativas a la prisión preventiva. Lo que estoy diciendo en este artículo lo puedo 


\section{El Abuso de los Jueces y Juezas al Dictar la Prisión Preventiva en Ecuador}

Vol. 1, núm. 4., (2017)

Elvis Guillermo Fuentes Tenorio; Marisol Katherine Castro Herrera; Susana Brasilia Cedeño Solórzano; Leopoldo Javier Larrea Simball

demostrar con un juicio que estaba llevando defendiendo a dos ciudadanos. Delgado y Bernardo quienes eran Agentes de Seguridad Penitenciaria en la cárcel conocida como el Centro de Privación de Libertad Regional Guayas, este caso se ventila en la UNIDAD JUDICIAL DE GARANTÍAS PENALES CON COMPETENCIA EN DELITOS FLAGRANTES DEL GUAYAS. Juicio \# 09281-2016-03191, por el supuesto delito de asociación ilícita sancionado en el Art. 370 del Código Orgánico Integral Penal, con pena privativa de libertad de tres a cinco años. Los jueces y juezas en este tipo de delitos pueden dictar medidas alternativas a la prisión preventiva, pero no lo hacen a pesar de que le demostramos un arraigo social, esto es una muestra más del abuso que se está realizando en nuestro país al dictar los jueces y juezas la prisión preventiva. (Subsecretaría de Desarrollo Normativo, 2014)

\section{La prisión preventiva}

\section{El derecho a libertad}

Es uno de los más preciados por el hombre. Es tal la importancia que se le atribuye, que tal vez sea el único bien y el único derecho que todo individuo está dispuesto a defender y a preservar poniendo en juego, no solamente su patrimonio sino también su propia integridad física y su vida cuando su privación se torna intolerable. (Parent Jacquemin, 2000)

\section{La prisión preventiva es una medida cautelar}

De carácter personal que afecta el derecho a la libertad de las personas por un lapso prolongado de seis meses en los delitos sancionado con pena de prisión y a un año en los delitos sancionados con pena de reclusión, los jueces y juezas tienen bajo su responsabilidad que estas 


\section{El Abuso de los Jueces y Juezas al Dictar la Prisión Preventiva en Ecuador}

Vol. 1, núm. 4., (2017)

Elvis Guillermo Fuentes Tenorio; Marisol Katherine Castro Herrera; Susana Brasilia Cedeño Solórzano; Leopoldo Javier Larrea Simball

prisión preventiva dictada por ellos no exceda los límites que establece nuestra Constitución de la República en su art. 77 numeral 9, si se exceden estos plazos la orden prisión preventiva quedaría sin efecto; esto quiere decir que la persona proceda obtendría inmediatamente su libertad. Pero este mismo Art. 77 de la Constitución en el inciso segundo establece algunas causas que impedirían que el procesado obtenga su libertad, si por cualquier medio la persona procesada ha evadido, retardado o evitado su juzgamiento mediante actos orientados a provocar la caducidad. Si se comprueba que esta persona proceda, realizo todos estos actos la prisión preventiva seguiría vigente y no podría obtener su libertad. Creemos que se está forzando al procesado a que se someta a la justicia de cualquier manera o sea que la persona privada de la libertad debe decirle al estado júzguenme ante de llegar al límite de caducidad la prisión preventiva dictada en mi contra, el deseo de libertad es algo innato en los seres humanos y forzarlo a que el ayude en su juzgamiento es violatorio al principio de inocencia. (Kostenwei, 2015)

\section{La prisión preventiva debería proceder}

Solo si las demás medidas cautelares fueren insuficientes para asegurar los objetivos que la generaron cual es el juzgamiento del procesado. Pero en Ecuador la prisión preventiva es utilizada por los jueces y juezas de manera excesiva y abusiva, ya que le da temor utilizar las otras medidas alternativas a la prisión preventiva, porque nuestra sociedad no las ve con buenos ojos.

Cuando se dicta la prisión preventiva al procesado por un delito este está obligado a ingresar a la cárcel, durante el tiempo que dure la investigación fiscal de esta manera tenemos un 


\section{El Abuso de los Jueces y Juezas al Dictar la Prisión Preventiva en Ecuador}

Vol. 1, núm. 4., (2017)

Elvis Guillermo Fuentes Tenorio; Marisol Katherine Castro Herrera; Susana Brasilia Cedeño Solórzano; Leopoldo Javier Larrea Simball

percepción que nuestra sociedad está tranquila, ya que decimos tenemos a los malos en nuestras prisiones donde sufrirán por el mal cometido. Por temor a la reacción social los jueces y juezas no dictan medidas alternativas a la prisión preventiva. Para ellos es más dictar la prisión preventiva hasta en los delitos de baja cuantía así se abusa en nuestro país de la prisión preventiva. PRISIÓN PREVENTIVA: USO RACIONAL (Zambrano Pasquel, 2009), nos dice que "La prisión preventiva - que llega a convertirse en una forma de pena anticipada aunque no sea esa su finalidad-, no debe ser manifiestamente violatoria de cualquier presupuesto de política criminal y de racionalidad, pues es una forma preponderante de coerción penal que produce como principales efectos los desintegradores de la personalidad, como la despersonalización, prisonización, etiquetamiento, etc., que funcionan como operadores de futuras conductas desviadas y como reforzadores de estigmatización cuando se trata de la prisión preventiva”.

Es claro el tratadita cuando compara a la prisión preventiva con una pena anticipada, porque al dictarla indiscriminadamente se viola el principio de inocencia.

\section{Requisitos que necesitan los jueces y juezas para dictar la prisión preventiva}

Estos requisitos utilizados en nuestro país a los utilizados por la justicia de países americanos y europeos son muy parecidos. Entre los requisitos más comunes tenemos:

a) Que haya fuertes indicios de culpabilidad

b) Que exista riesgo de fuga que puede poner en peligro el cumplimiento de la condena (si el juicio finalizase con una sentencia de culpabilidad).

c) Que pueda destruir pruebas, suponga un peligro para la víctima, o para evitar el riesgo de que pueda cometer otros hechos delictivos (en el caso de algunos delitos graves) 


\section{El Abuso de los Jueces y Juezas al Dictar la Prisión Preventiva en Ecuador}

Vol. 1, núm. 4., (2017)

Elvis Guillermo Fuentes Tenorio; Marisol Katherine Castro Herrera; Susana Brasilia Cedeño Solórzano; Leopoldo Javier Larrea Simball

d) Normalmente la prisión preventiva se decreta cuando no existe otro método más eficaz.

e) Es la última opción. Pero siempre preferible utilizar otras medidas cautelares de menor entidad como por ejemplo: el arresto domiciliario o una caución económica (fianza).

Nuestro Código orgánico Integral Penal, estable los siguientes requisitos para que un juez o jueza pueda dictar la prisión preventiva.

Artículo 534.- finalidad y requisitos.- Entre las finalidades porque el juez o jueza deba dictar la prisión preventiva tenemos:

a) Garantizar la comparecencia de la persona procesada al proceso o sea durante el tiempo de que dure el juicio.

b) El cumplimiento de la pena, esto quiere decir que si en el transcurso del proceso se determina culpabilidad y esta persona obtiene una sentencia condenatoria, se ratificaría la prisión preventiva y se le obligaría a cumplir la pena impuesta por el juez o tribunal penal.

Los requisitos para que un juez o jueza pueda dictar la prisión preventiva son los que están establecidos en nuestro derecho penal positivo y son los siguientes:

a) Elementos de convicción suficientes sobre la existencia de un delito de ejercicio público de la acción.

b) Elementos de convicción claros y precisos de que la o el procesado es autor o cómplice de la infracción. Cuando el código orgánico integral penal como se llama a nuestra ley penal en Ecuador, se refiere a elementos de convicción se Relaciona a las evidencia que 


\section{El Abuso de los Jueces y Juezas al Dictar la Prisión Preventiva en Ecuador}

Vol. 1, núm. 4., (2017)

Elvis Guillermo Fuentes Tenorio; Marisol Katherine Castro Herrera; Susana Brasilia Cedeño Solórzano; Leopoldo Javier Larrea Simball

la fiscalía tiene a su favor para proponer una acusación en contra de una persona que se presuma que fue el autor de un delito y estos elementos lo integran el resultado de las diligencias practicadas en la fase preparatoria, conducentes a la determinación de los hechos punibles y a la identificación de los autores y partícipes, sirviendo de evidencias contundentes para solicitar el enjuiciamiento de una persona y probar su culpabilidad.

c) Indicios de los cuales se desprenda que las medidas cautelares no privativas de la libertad son insuficientes y que es necesaria la prisión preventiva para asegurar su presencia en el juicio o el cumplimiento de la pena. En este requisito el legislador trata de decirnos que la persona procesada sino le dictan inmediatamente los jueces o juezas la prisión preventiva por la peligrosidad del delito, podría huir escondiendo de la justica, para de esta manera lograr una prescripción de la acción.

d) Que se trate de una infracción sancionada con pena privativa de libertad superior a un año. De ser el caso, la o el juzgador para resolver sobre la prisión preventiva deberá tener en consideración si la o el procesado incumplió una medida alternativa a la prisión preventiva otorgada con anterioridad.

e) Elementos de convicción claros y precisos de que la o el procesado es autor o cómplice de la infracción. Cuando el código orgánico integral penal como se llama a nuestra ley penal en Ecuador, se refiere a elementos de convicción se Relaciona a las evidencia que la fiscalía tiene a su favor para proponer una acusación en contra de una persona que se presuma que fue el autor de un delito y estos elementos lo integran el resultado de las diligencias practicadas en la fase preparatoria, conducentes a la determinación de los 


\section{El Abuso de los Jueces y Juezas al Dictar la Prisión Preventiva en Ecuador}

Vol. 1, núm. 4., (2017)

Elvis Guillermo Fuentes Tenorio; Marisol Katherine Castro Herrera; Susana Brasilia Cedeño Solórzano; Leopoldo Javier Larrea Simball

hechos punibles y a la identificación de los autores y partícipes, sirviendo de evidencias contundentes para solicitar el enjuiciamiento de una persona y probar su culpabilidad.

f) Indicios de los cuales se desprenda que las medidas cautelares no privativas de la libertad son insuficientes y que es necesaria la prisión preventiva para asegurar su presencia en el juicio o el cumplimiento de la pena. En este requisito el legislador trata de decirnos que la persona procesada sino le dictan inmediatamente los jueces o juezas la prisión preventiva por la peligrosidad del delito, podría huir escondiendo de la justica, para de esta manera lograr una prescripción de la acción.

g) Que se trate de una infracción sancionada con pena privativa de libertad superior a un año. De ser el caso, la o el juzgador para resolver sobre la prisión preventiva deberá tener en consideración si la o el procesado incumplió una medida alternativa a la prisión preventiva otorgada con anterioridad.

“La Corte Interamericana de Derechos Humanos en diversas sentencias, como el Caso Bayarri contra Argentina, párrafo 69, o el Caso Acosta Calderón contra Ecuador, párrafo 74, igualmente ha señalado que la prisión preventiva es la medida más severa que se puede aplicar a una persona a la cual se le imputa un delito, por lo cual su aplicación debe tener carácter excepcional, limitado por el Principio de Legalidad, la presunción de inocencia, la necesidad y proporcionalidad, de acuerdo con lo que es estrictamente necesario en una sociedad democrática, agregando que: "es una medida cautelar, no punitiva"

La corte interamericana de derechos Humanos ha sancionado al ecuador por violador los derechos humanos de los ciudadanos y por el abuso que realizan sus jueces y juezas al dictar la prisión preventiva. 


\section{El Abuso de los Jueces y Juezas al Dictar la Prisión Preventiva en Ecuador}

Vol. 1, núm. 4., (2017)

Elvis Guillermo Fuentes Tenorio; Marisol Katherine Castro Herrera; Susana Brasilia Cedeño Solórzano; Leopoldo Javier Larrea Simball

El profesor (Ore Guardia, 1996), de la Universidad Nacional Mayor de San Marcos y la Pontificia Universidad Católica, ha publicado un texto universitario dedicado al Derecho procesal penal. LAS MEDIDAS CAUTELARES PERSONALES en el PROCESO PENAL PERUANO, Grafica intensamente el Principio de Proporcionalidad, en la forma siguiente:

“Consideramos que resulta desproporcionado que ante delitos de menor gravedad o poca daño social se restrinja la libertad ambulatoria de los procesados, por cuanto ello implica desconocer los efectos criminógenos de las privaciones de la libertad de corta duración, la desnaturalización de una medida excepcional de naturaleza procesal, así como la entronización de la detención como verdadero anticipo de la pena."

Este conocido jurista peruano, hace hincapiés de que la prisión preventiva no debe dictarse en los delitos de menor gravedad o mínima cuantía, porque para él se desnaturaliza una mediada de carácter excepcional, que solo debe ser dictada en los delitos graves, pero siempre y cuando ya no haya posibilidad de dictar otras de las medidas alternativas a la prisión preventiva. (Oré Guardia, 2011)

\section{Posición crítica frente a la prisión preventiva y a su aplicación.}

Es contraria al principio democrático de la "presunción de inocencia", puesto que pena al acusado aún antes de que se haya demostrado su culpabilidad, siendo imposible de reparar el daño que se le cause en el caso de que finalmente sea declarado inocente daña seriamente la imagen, reputación, vida laboral y privada de los imputados. En determinados países se abusa de esta medida cautelar, tanto en el número de presos como en la duración de la misma. 


\section{El Abuso de los Jueces y Juezas al Dictar la Prisión Preventiva en Ecuador}

Vol. 1, núm. 4., (2017)

Elvis Guillermo Fuentes Tenorio; Marisol Katherine Castro Herrera; Susana Brasilia Cedeño Solórzano; Leopoldo Javier Larrea Simball

En nuestro país la prisión preventiva tiene una duración de un año en los delitos sancionados con reclusión (Encierro forzoso de una persona en un lugar). Y de seis meses en los delitos sancionados con prisión (Pena de privación de libertad que es inferior a la reclusión) estamos convencido que nuestro país debe tener un cambio de cultura judicial ya que nuestra constitución es clara al presumir la inocencia de toda persona y la única forma de destruir este principio es a través de una sentencia ejecutoriada, el COIP. También fortalece este principio en el Art. 5 numeral 4, este principio impone al sistema judicial ciertas limitaciones y obliga que al procesado se lo mire como inocente, esto es una prueba más de incompatibilidad de la las medidas cautelares y con la prisión preventiva, por tal razón los jueces y juezas deben dictarla como última instancia.

La efectividad de la intervención penal ha sido cuestionada desde hace tiempo al considerar que la respuesta del Estado siempre llega tarde, esto es, cuando el daño se ha producido, razón por la cual no logra el efecto preventivo, que la sociedad espera de la estructura estatal legal judicial organizada. La solución propuesta por la doctrina a este desfase es la creación de los delitos de peligro, la que evidentemente obedece a un criterio expansionista del derecho penal pero que encuentra plena aceptación en la tendencia moderna, donde ya no se trata tanto de la sola protección del bien jurídico sino de la protección de instituciones sociales o unidades funcionales de valor (como la salud pública o el medio ambiente en sentido amplio), con lo que el efecto preventivo llega con mayor facilidad en el momento que la protección del ordenamiento es más institucional.

Sentencia de mala calidad por parte de un juez: 


\section{El Abuso de los Jueces y Juezas al Dictar la Prisión Preventiva en Ecuador}

Vol. 1, núm. 4., (2017)

Elvis Guillermo Fuentes Tenorio; Marisol Katherine Castro Herrera; Susana Brasilia Cedeño Solórzano; Leopoldo Javier Larrea Simball

Son varias las razones entre las que destacamos: Falta de preparación profesional e ineptitud.

Hay Jueces que actúan razonablemente, están preparados y son éticos en su trabajo. Sin embargo las sentencias siguen siendo muy malas la mayor parte de las veces porque no tienen el suficiente argumento jurídico al momento de dictarlas.

\section{Proceso de función judicial en ecuador}

En la actualidad los jueces están utilizando herramientas de gran ayuda como son las nuevas tecnologías que son fundamentales y entre ellas son:

- La videoconferencia, plataformas y learning.

\section{Conclusiones}

Un delito es un comportamiento contrario al ordenamiento jurídico establecido, que se realiza, por imprudencia o voluntad propia y el que lo comete se hará merecedor a una pena previo un debido proceso. Estoy de acuerdo con lo manifestado con el (Zaffaroni, 2015), en una entrevista de prensa en la Argentina donde lo consultaron sobre la prisión preventiva, el respondió

"si me pongo en teórico puro nunca hay que dictar la prisión preventiva porque se trata de una pena anticipada. Obviamente la preventiva es indispensable cuando hay que interrumpir un curso delictivo, desarmar una organización delictiva, cuando el sujeto puede alterar pruebas o amenazar y cuando el hecho es de gravedad. La preventiva nunca tiene del todo racionalidad 


\section{El Abuso de los Jueces y Juezas al Dictar la Prisión Preventiva en Ecuador}

Vol. 1, núm. 4., (2017)

Elvis Guillermo Fuentes Tenorio; Marisol Katherine Castro Herrera; Susana Brasilia Cedeño Solórzano; Leopoldo Javier Larrea Simball

pero fuera de esos casos tiene menos.", este pensamiento de unos de los juristas americanos más respetado de los últimos tiempos, me da fuerzas y ratifica lo dicho en este art. Que los jueces y juezas son groseros al momento de dictar la prisión preventiva, este mismo escritor nos da en la mencionada entrevista de prensa una gran reflexión donde sin pelos en la lengua nos dice:

"La prisión preventiva hay que manejarla con mucho cuidado. Cualquiera de nosotros puede estar seguro de que nunca vamos a cometer un delito, pero no podemos estar seguros de que no seremos sospechosos de cometer un delito. Estamos hablando de gente que no es culpable" afirmó. (Zaffaroni, 2015), esto demuestra que los jueces y juezas deben reflexionar mucho al momento de dictar la risión preventiva, porque mañana podrían ser ellos lo que se vean en calidad de sospecho de cometer un delito puede ser dentro de sus funciones o fuera de ellas. Pienso que la prisión preventiva solo debe dictarse en los casos que causen gran alarma social y previa evidencias bien sustentadas que contenga la fiscalía, en los demás casos se debe dictar medidas alternativas a la prisión preventiva. Aplicar esta medida que debe ser obligaría para los jueces y juezas causara protesta en nuestra sociedad que está acostumbrada a ver a los ciudadanos que violaron la ley en la cárcel. Pero con el paso del tiempo se acostumbraran y respetaran las decocciones de nuestros jueces y juezas. La justicia no debe ser referida siempre al castigo como consecuencia del mal comportamiento, entre el sistema judicial y la sociedad están impregnadas estas frases, a todos los malos se los debe meter a la cárcel, todos los asesinos y ladrones deben estar en las cárceles es la única forma de aplicar justicia todo lo que tiene que ver con la cárcel es para nuestra sociedad una verdadera justicia.

El Juez es el profesional clave para dirigir la audiencia siendo conciliador, colaborador y no oponerse entre las partes. 


\section{El Abuso de los Jueces y Juezas al Dictar la Prisión Preventiva en Ecuador}

Vol. 1, núm. 4., (2017)

Elvis Guillermo Fuentes Tenorio; Marisol Katherine Castro Herrera; Susana Brasilia Cedeño

Solórzano; Leopoldo Javier Larrea Simball

\section{Bibliografía.}

Asamblea Constituyente del Ecuador. (2008). Constitucion del Ecuador. Montecristi: autor.

Kostenwei, E. (2015). La prisión preventiva: interpretando su estructura. Prisma Jurídico, 14(2), 55-83.

Ore Guardia, A. (1996). Manual de Derecho Procesal Penal. Lima: Alternativas.

Oré Guardia, A. (2011). LAS MEDIDAS CAUTELARES PERSONALES. En A. Oré Guardia, PROCESO PENAL PERUANO (pág. 34). Lima: Reforma.

Parent Jacquemin, J. (2000). La Libertad: Condición de los Derechos Humanos. Convergencia. Revista de Ciencias Sociales, 7(22), 143-158.

Subsecretaría de Desarrollo Normativo. (2014). Código Orgánico Integral Penal. Quito: Ministerio de Justicia, Derechos Humanos y Cultos.

Zaffaroni, R. (02 de 04 de 2015). La prisión preventiva no tiene racionalidad en los delitos de menor gravedad. (E. Ortiz, Entrevistador) $8300 \mathrm{Web.}$

Zambrano Pasquel, A. (2009). Manual de Práctica Procesal Penal. Quito: Edilex. 


\section{El Abuso de los Jueces y Juezas al Dictar la Prisión Preventiva en Ecuador}

Vol. 1, núm. 4., (2017)

Elvis Guillermo Fuentes Tenorio; Marisol Katherine Castro Herrera; Susana Brasilia Cedeño Solórzano; Leopoldo Javier Larrea Simball

"La aspiración innata del hombre a la libertad es invencible; puede ser aplastada pero no aniquilada. El estado totalitario no puede renunciar a la violencia. Si lo hiciera perecería. La eterna, ininterrumpida violencia, directa o enmascarada, es la base del Estado totalitario. El hombre no renuncia a la libertad por propia voluntad. En esta conclusión se halla la luz de nuestros tiempos, la luz del futuro."

\section{Vasili Grossman Vida y Destino}

“Ahí lo tienes -dijo la Reina- está encerrado en la cárcel, cumpliendo su condena; pero el juicio no empezara hasta el próximo miércoles. Y por supuesto, el crimen será cometido al final"

"En un ataque de furia gritó la Reina: ¡Deténganla! ¿Por qué motivo se preguntó Alicia? Porque has cometido un crimen y hasta que se descubra lo que has hecho irás a la prisión, así es la ley.” 
El Abuso de los Jueces y Juezas al Dictar la Prisión Preventiva en Ecuador

Vol. 1, núm. 4., (2017)

Elvis Guillermo Fuentes Tenorio; Marisol Katherine Castro Herrera; Susana Brasilia Cedeño Solórzano; Leopoldo Javier Larrea Simball

Las aventuras de Alicia en el país de las maravillas 